It is tempting to associate this condition with some form of myotonia. Both acetylcholine and anticholinesterase drugs (e.g., neostigmine) can increase the myotonic response. Similarly, suxamethonium has been known to cause such a response in patients with myotonia congenita, and this combination was thought to be responsible for the hyperpyrexia in one case. ${ }^{6}$ Nevertheless, in other cases biopsies of muscle did not show any signs of myopathy. ${ }^{7}$

Animals anaesthetized with agents similar to those used in man have not developed hyperpyrexia. L. W. Hall and his colleagues, ${ }^{8}$ however, described three pigs of the same litter which were given suxamethonium during anaesthesia with phencyclidine and halothane and which all developed a rise in body temperature. Other pigs did not show this response. They suggested, therefore, that there might be a genetic or constitutional abnormality present in which the suxamethonium acted as a trigger for the hyperpyrexial reaction. M. A. Denborough and his colleagues ${ }^{9}$ reported the anaesthetic history of a family in which ten deaths occurred after anaesthesia ; at least three of these patients had a high temperature at the time of death. Some of them were exposed to neither halogenated hydrocarbons nor muscle relaxants. On the other hand, the appearance of hyperpyrexia in five unrelated patients in one hospital in a week makes it unlikely that a genetic factor alone is responsible. ${ }^{10}$

F. L. Hoch ${ }^{11}$ has attributed the hyperpyrexia seen during thyrotoxic crisis to an uncoupling of oxidative phosphorylation, and R. D. Wilson and his colleagues ${ }^{12}$ have shown that the uncoupling of oxidative phosphorylation which is produced in dogs by the administration of 2,4-dinitrophenol is enhanced by the administration of halothane; they suggested that the same process, in which the halogenated hydrocarbon acts as a trigger mechanism, may be responsible for the hyperpyrexia in humans. But halogenated hydrocarbons were not used in all the cases, and D. R. Challoner ${ }^{13}$ has suggested that hypermetabolic states may be initiated through metabolic pathways that are not associated with high energy phosphate metabolism. Psychotherapeutic drugs which have specific biochemical effects on the central nervous system may also produce hyperpyrexia with clinical features closely resembling those described in the anaesthetic cases, including increased muscle tone. ${ }^{14}$

So the aetiology of this new syndrome remains baffling, mainly because of the wide variety of circumstances in which it has been reported. Nevertheless, the bulk of opinion favours a cause-and-effect relationship between suxamethonium and increased muscle metabolism probably occurring in patients with some congenital abnormality such as latent myotonia.

\footnotetext{
Stephen, C. R., f. Amer. med. Ass., 1967, 202, 178. Allen, C. R., f. Amer. med. Ass., 1967, 202, 183.

- Pinson, K. B., Brit. med. F., 1927, 1, 957.

- Modell, J. H., Anesthesiology, 1966, 27, 329.

- Relton, J. E. S., Creighton, R. E., Johnston, A. E., Pelton, D. A., and Conn, A. W., Canad. Anaesth. Soc. F., 1966, 13, 419.

- Saidman, L. J., Havard, E. S., and Eger, E. I., f. Amer. med. Ass. 1964, 190, 1029.

'Thut, W. H., and Davenport, H. T., Canad. Anaesth. Soc. F., 1966, $13,425$.

- Hall, L. W., Woolf, N., Bradley, J. W. P., and Jolly, D. W., Brit. med. 7., 1966, 2, 1305.

Denborough, M. A., Forster, J. F. A., Lovell, R. R. H., Maplestone, P. A., and Villiers, J. D, Brit. F. Anaesth., 1962, 34, 395.

10 Papper, E. M. personal communication, 1968.

11 Hoch, F. L., Nerw Engl. ₹. Med., 1962, 266, 498.

Wilson, R. D., Nichols, R. J., Dent, T. E., and Allen, C. R., Anesthesiology, 1966, 27, 231 .

1. Challoner, D R., Lancet, 1966, 2, 681.

1. Stanley, B., and Pal, N. R., Brit. med. F., 1964, 2, 1011 ; Bowen, L. W., Brit. med $7 . .1964,2,1465$.
}

Another mystery is the small number of cases that have occurred in Britain. It is possible that some have not been reported-in only one of the three English cases was hyperpyrexia mentioned on the death certificate. Wider publicity for this syndrome may bring further cases to light. Since both hyperpyrexia and hypothermia may occur in patients undergoing anaesthesia, it is important that the body temperature should be monitored. The onset of a rapid rise in body temperature must be regarded as potentially lethal because only the most drastic methods of body cooling, internal or external, are likely to be effective.

\section{Coxsackie Virus Infections}

In 1948 G. Dalldorf and G. M. Sickles ${ }^{1}$ isolated a new agent from the faeces of two children with paralytic poliomyelitis. It had the unusual feature of being pathogenic for newborn mice and hamsters but caused no disease in rhesus monkeys. Soon afterwards J. L. Melnick and colleagues ${ }^{2}$ reported the isolation of similar agents (now identified as viruses) from cases of non-paralytic poliomyelitis or aseptic meningitis, and it was clear from this report that more than one antigenic type of this virus existed. The original strains of these viruses were isolated from the township of Coxsackie on the Hudson River in New York State and they were provisionally named the Coxsackie group of viruses. Later in 1962 the term Coxsackie virus was accepted and has been used ever since.

Many antigenic types are now known. Because of the striking biological property of virulence for immature mice and hamsters it has been found possible to divide the Coxsackie viruses into two main groups on the basis of the histopathological appearance of the lesions in infected mice. Group A strains, comprising 24 serological subtypes, produce in mice a flaccid paralysis as a result of diffuse myositis, whereas group B strains, comprising six subtypes, produce spastic paralysis with focal necrosis of muscle, brown fat, encephalomalacia, and focal necrosis in the pancreas, liver, and myocardium.

Concurrently with the recognition of the Coxsackie viruses came the important discovery of J. F. Enders and colleagues ${ }^{3}$ that polioviruses could be cultivated in cell cultures of nonneural tissue. Within a surprisingly short time, as a result of these techniques of cell culture and inoculation of immature mice, a large number of enteric viruses were identified, falling into three main groups. These are, firstly, the polioviruses, responsible mainly for paralytic disease and pathogenic for monkeys; secondly, the Coxsackie viruses, pathogenic for immature mice and hamsters ; and, thirdly, the E.C.H.O. viruses, which are non-pathogenic for animals. With few exceptions viruses of all three groups can be cultivated in cell cultures, and show a varying degree of pathogenicity for man.

The Coxsackie viruses have been encountered in all parts of the world. They can be recovered from human faeces, nasopharyngeal secretions, and sewage. The frequency of virus excretion is higher in the lower than the upper socioeconomic groups. Coxsackie viruses are more prevalent in the summer and early autumn. Changes in the incidence of Coxsackie viruses and polioviruses followed the introduction of mass immunization against poliomyelitis. There is 
an inverse relationship between the isolation of Coxsackic B strains and the incidence of paralytic poliomyelitis, whereas no such interference has been noted between the A strains and poliomyelitis. Indeed, it is of interest to recall that the first two children from whom Coxsackie A strains were isolated were paralysed, ${ }^{1}$ but they were also found to be excreting poliovirus. ${ }^{4} \mathrm{~J}$. Gear and his colleagues ${ }^{5}$ have recorded similar observations.

Coxsackie A strains have been identified as a cause of herpangina, the closely related syndrome of acute lymphonodular pharyngitis, hand-foot-and-mouth disease, and some cases of aseptic meningitis. Last year in Great Britain A strains were isolated during outbreaks of hand-foot-andmouth disease, and recently $M$. F. Duff ${ }^{6}$ has reported the isolation of Coxsackie A10 virus from cases with this clinical syndrome observed in Wellington, New Zealand, in the autumn of 1965. Cases of hand-foot-and-mouth disease have been reported from all over the world. They often occur in outbreaks and as family infections. Coxsackie viruses A16, A10, and other A strains have been isolated from patients presenting with fever, oral vesicles, or blisters, and a vesicular or maculopapular rash on the hands and feet. The condition is in no way related actiologically to bovine foot-andmouth disease..$^{i 8}$

Coxsackie $B$ strains have been identified as causes of aseptic meningitis, Bornholm disease, myocarditis, pericarditis, acute meningoencephalitis with myocarditis in the newborn, and undifferentiated febrile and respiratory illness. Many cases of Coxsackie B virus infection were identified in Britain in 1965. For instance, Joan Carmichael and her colleagues $^{0}$ have recently reported an outbreak of B2 infection in a residential nursery. It started with an acute onset of cough and cyanosis in a 3-year-old child, and other signs and symptoms pointed to inhalation of a foreign body. On admission to hospital the child was found to be suffering from an acute respiratory infection, and the following day seven further children became ill with fever, drowsiness, a dry cough, and diarrhoea and vomiting. Coxsackie B2 was isolated from a number of patients. This week in the B.M.f. at page 97, Dr. M. Helin and co-workers in Helsinki report on a widespread epidemic of Coxsackie B5 in Finland in the autumn of 1965 , in which they observed 18 cases with cardiac involvement. All the patients, aged 8-65 years (mean 28 years), had fever. Six showed signs of pericarditis with chest pain, pericardial rub, electrocardiographic changes, and radiological evidence of enlargement of the heart. Five patients showed signs of aseptic meningitis.

Coxsackie virus B strains behave rather like herpesvirus in that they tend to produce more serious disease with disseminated lesions in the newborn and young infants, whereas in older children and adults the infection tends to be more localized. These reports are a further reminder that the non-poliomyelitis enteric viruses may cause substantial outbreaks of disease, and as poliomyelitis is progressively elimi-

1 Dalldorf, G., and Sickles, G. M., Science, 1948, 108, 61.

2 Melnick, J. L., Shaw, E. W., and Curnen, E. C., Proc. Soc. exp. Biol. (N.Y.), 1949, 71, 344.

${ }^{3}$ Enders, J. F., Weller, T. H., and Robbins, F. C., Science, 1949, 109,

45. Dalldorf, G., f. Mt Sinai Hosp., 1952, 19, 396.
. Gear, J., Measroch, V., and Prinsloo, F. R., S. Afr. med. F., 1956, 30,

'Duff, M. F., Brit. med. F., 1968, 2, 661.

Armstrong, R., Davie, J., and Hedger, R. S., Brit. med. f., 1967, 4, 529.

- Brit. med. F., 1967, 4, 503.

Carmichael, J., McGuckin, R., and Gardner, P. S., Brit. med. F., 1968. 2,532 . nated it seems probable that more will be heard of Coxsackie and E.C.H.O. viruses.

\section{Chemotherapy of Malaria}

Interest in research into malaria temporarily waned some years ago after the successful introduction of the synthetic antimalarial drugs and the malaria eradication campaigns by the World Health Organization. Strains of Plasmodium falciparum resistant to the 4-aminoquinolines have now been reported in Venezuela, Colombia, Brazil, Thailand, West Malaysia, Cambodia, and Vietnam, and this has led to a considerable resurgence of interest in experimental malaria chemotherapy ${ }^{1}$ and has emphasized the urgent need for new antimalarial drugs. ${ }^{2}$ Resistance to chloroquine shows a gradation from a loss of effect which leads to occasional recrudescence to a resistance so marked that the drug has no apparent effect on symptoms and parasitaemia. ${ }^{3}$ Despite considerable research the mechanisms of resistance of malaria parasites to drugs are not well understood. A number of strains of $P$. falciparum that are resistant to chloroquine also show resistance to the other synthetic antimalarial drugs and in some instances even to quinine. Fortunately reports of chloroquine resistance in various parts of Africa have not been substantiated, while the other species of malaria that affect man $-P$. vivax, $P$. malariae, and $P$. ovale-are still sensitive to the 4-aminoquinolines.

In most areas the drugs of choice for chemosuppression in individual patients are still proguanil 100-200 mg. daily or pyrimethamine $25-50 \mathrm{mg}$. weekly. It is not wise to use chloroquine as the mainstay of prophylaxis. The search for long-acting antimalarials has led to the development of cycloguanil embonate, which is used either alone or in combination with 4,4'-diacetyldiamino-diphenylsulfone (D.A.D.D.S.). In endemic areas the action of these repository preparations has been disappointingly short and their usefulness is limited by their tendency to cause resistance. Potentiating mixtures of pyrimethamine and sulphonamides and pyrimethamine and sulfones are undergoing field trials with encouraging results. These combinations are also effective against drug-resistant malaria.

Except in chloroquine-resistant cases, the 4-aminoquinolines should be used for the treatment of an acute attack of malaria. In areas where chloroquine-resistance has occurred most infections, but not all, can be controlled by the administration of quinine. The majority of patients that do not respond to quinine can be cured by a single oral dose of $1 \mathrm{~g}$. of sulformethoxine with $50 \mathrm{mg}$. of pyrimethamine.*

Though the resistance of malaria parasites to 4-aminoquinolines has not so far created serious problems for malaria eradication programmes, they may occur in the future, and new antimalarials are urgently required. Ideally, these should be effective against sporozoites and should have a prolonged action and a low tendency to induce resistance. New chemical types are needed for treating infections that are resistant to the limited range of drugs presently available. An antimalarial with all the above properties is likely to be difficult to find, but a drug satisfying some of the needs is certainly not beyond the achievements of modern chemotherapy and research.

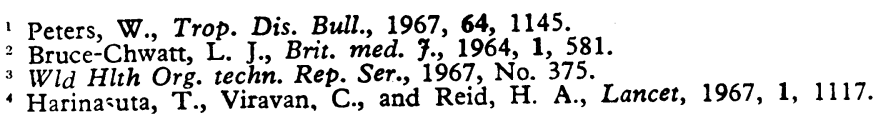

